\title{
EAl Endorsed Transactions

\section{Learning by playing: An LBG for the Fortification Gates of the Venetian walls of the city of Heraklion}

\author{
Kostas Vassilakis, Orestis Charalampakos, Georgios Glykokokalos, Persefoni Kontokalou, Michail \\ Kalogiannakis, Nikolas Vidakis*
}

Dept. of Informatics Engineering, Technological Education Institution of Crete, Stauromenos, 71410, Heraklion, Greece

\section{Abstract}

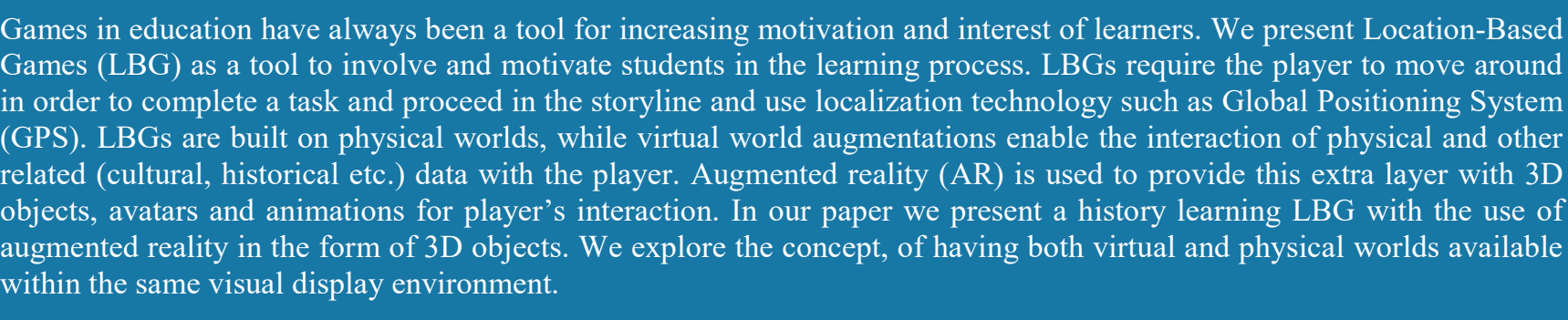

Keywords: Game-based learning (GBL), location based educational games, mobile learning, augmented reality (AR), digital storytelling, education outside the class, Global Positioning System (GPS).

Received on 31 May 2018, accepted on 14 July 2018, published on 18 July 2018

\begin{abstract}
Copyright (C) 2018 Kostas Vassilakis et al., licensed to EAI. This is an open access article distributed under the terms of the Creative Commons Attribution licence (http://creativecommons.org/licenses/by/3.0/), which permits unlimited use, distribution and reproduction in any medium so long as the original work is properly cited.
\end{abstract}

doi: 10.4108/eai.7-3-2019.156773

"Corresponding author. Email:Nv@ie.teicrete.gr

\section{Introduction}

Games play a significant part in human life especially in the early stages of growth. Game is a part of the procedure through which a child shapes his character his behavior and his personality. The game at the first years of a child's life helps the evolution of the comprehension, the imagination and the obedience in ethical rules [1]. With games children as much as adults, are being socialized, discover and absorb new knowledge in a funny and carefree way.

With the growth of technology digital games have been developed and a new age in Game-Based Learning had arisen. Nowadays every child has grown up in an environment with tablets, laptops and smartphones. Gamebased learning has its own evolvement with digital games. Even games that are not designed to be used in education have correct content or simulating real-world situation [2].
Gaming has always been a fun way to learn new things and acquire skills. Many learning theories align with the gaming process [3]. In games students are highly motivated by involvement with the subject of study and stimulation comes with learning by doing. Gamification applies game elements to real life tasks. In this way, it helps in the behavioral change, improves motivation and enhances engagement [3] [4]. Furthermore, the constructivism theory is embedded in Game- Based learning approach [5].

Ubiquitous computing [6] which describes the technology and the use of a computer that is not static could be the early foundations of Mobile Computing and Location Based Games. In the middle of the 90 s mixed reality was in attention. In [7] Miligram argues: "The next generation telecommunication environment is envisaged to be one, which will provide an ideal virtual space with [sufficient] reality essential for communication".

Mobile computing among wireless networks allowed, users to have access in content, apps, games and more from everywhere at any time. The combination of mobility and wireless networking [8] had as an outcome the tremendous 
growth of mobile apps to support almost anything. A description of our days could be that is the age of information at our fingertips according to Bill Gates. Smartphones are the most common handheld devices that made this vision, reality. Over 2.5 billion is forecast to be the smartphone users by 2019. About 36 percent of the world's population is estimated that uses a smartphone [9] [10].

In an era where almost everyone has a mobile device is more than common sense that learning process is adjusting, not just in the mobility of the device that provide the content but from the aspect of the mobile technology as a participant in this procedure. Between the participants, learners, technology and other elements, of this learning system and their interactions knowledge is come into existence and being absorbed [11].

Mobile computing and the localization technology opened a new way in gaming and mobile learning [12]. Mobile devices are used to determine players' location and provide them with the relevant content. The field of the game is beyond the screen of the device, extends to the real world. Digital content is combined with physical things, locations, enriching the gaming and the learning experience. Location Based Games have met high interest in recent years. Both in academia as also in industry, games which are based in determining player's location have gained more space. "Pokémon GO" is a successful paradigm of such a game with more than 500 million downloads and the players walked more than 4.6 billion kilometers during gameplay [13].

The use of LBGs can be something more from just playing around. In many sectors such as tourism or education these games are increasing the motivation and provide the necessary guidance to the participants through this procedure. The value added in learning process turns out from the fact that the learning material, is embedded in the real world which exceed the traditional formal educational ways [14].

A ludic LBG must have the right content and a very meticulous design to fulfill its educational purpose. Therefore, a specialist needed to create the content and design the learning path through the game. In a LBG used in tourism a tour guide is needed to indicate the content to be displayed when the tourist arrives in a spot with an attraction as also the correct sequence of this content. In an educational LBG an educational expert is needed to design the learning path through the game, the given knowledge at each time. In both cases a programmer must intervene and create the game, write the code and the game functionality and embed the given content. More than one professionals with different eras of expertise must work together to produce a fully operational and educational LBG. Some researchers present even the learners as the designers of the LBG regarding this process to engage students with the educational content of the game, find and absorb new aspects around the topic [15].

The purpose of our game -The Heraklion Fortification Gates- is to provide the means for teaching the history of the Venetian walls of the city of Heraklion (Crete). Every time the players reach one of the nine gates/bastions of the walls, they get notifications to answer questions which are related to the history of that gate. Players visit the Fortification's gates all around the city and get information about them. The game ends when the players have passed all the Gates.

The rest of the paper is structured as follows. Section 2 presents the Background based on findings of the literature review conducted. Section 3 introduces the development of the Heraklion fortification gates game and Section 4 concludes the paper.

\section{Background}

With the growth of digital games there was a new academic interest in how gaming could contribute through new perspective in education.

Gamification in Education attempts to harness the power of videogames for motivation and put it into practice at classrooms [16]. Teachers achieve this, by translating the kind of engagement that students experience with games, into an educational context which includes influencing students' behavior and goals of facilitating learning [17] [18] [19]. The localization technology evolvement opens a new way in gaming and furthermore on Game-Based Learning. The arenas are now entire cities for many games [20]. Role-playing games, hunts and searching for treasures are just some of the types of Location Based games [21].

\subsection{Location Based Games \& Augmented Reality}

Location Based Games require the player to move around in order to complete a task and proceed further [22]. The basic idea with these games is that the players combine knowledge and physical activities that take place in the real world, especially in sights that are rich in educational value, like historic city centers [23].

The use of localization technology makes possible to locate the player's position and display the game elements depending on the location. Location Based Games are built upon the physical world, but with an addition of an extension of a virtual world which enables the interaction of physical and cultural items and linked-to them-data with the player. Therefore, some other terms are used as also for games with significant similarities with location-based, like "pervasive games", "mixed-reality games", "geogames" etc. [24] [25] [26].

Location Based Games are used for academic and pedagogic reasons. LBGs are ludic games which combine learning with pleasure [20]. The characteristics of such games enforce the ability to involve students into meaningful learning activities indoors and outdoors [27].

Augmented Reality (AR) is a technology that allows people to integrate virtual objects and live data directly on the user's surrounding environment [28]. Since 2000, many articles mention LBGs as the new trend. In the following years, more and more location based and AR applications 
were developed, especially for mobile equipment [29] [30]. "Pirates!" [31] is a multi-player game implemented on handheld devices connected in a Wireless Local Area Network (WLAN). The players in "Pirates!" used the physical environment as the game arena [31]. But there was no accuracy in determining the player's location and this assume limits on designing the game. The development in mobile computing and telecommunication with the global positioning system (GPS) was the next big step towards Location Based services and games. In 2003, the game "Can You See Me Now (CYSMN)" [32] was implemented with GPS technology. Players could move around within the cityarena with a fixed speed, they could see the city map and the position of the other players and they could also communicate with each other using walkie-talkies [32].

To serve the goal of education a game must provide the players-students with new information, or relate their background knowledge with the real world. In this case LBGs can connect digital media and metadata with the locations, cultural objects, monuments etc. for the learning gain [33]. This is consolidated by the fact that people are learning easily when they're combining words, patterns and other media within a structured learning environment, in comparison to the use of mere words according to the Cognitive Theory of Multimedia [34].

Augmented Reality elements and digital mapping can be implemented for the creation of educational material by using information on a geo-location with visual references to digital resources [35]. Virtual content could be anything, 3D scenes or objects, a textual display of the data. Augmented Reality enriches the sensorial perception of a person because she/he can see and hear more than others, and perhaps even touch, smell and taste things that others cannot [28]. The main task of AR in our game is the continuous calculation and replacement of the visual angle, so that the virtual image can be accurately projected on an object. Therefore, AR calculates the distance and orientation from the observation device to the predefined pattern in real world and accurately projects the setup model on that predefined pattern, by using computer vision technology.

The first educational location-based game with augmented reality elements was "Environmental Detectives" [36]. It was created by Massachusetts Institute of Technology (MIT) Teacher Educational Program (TEP) and it was targeted to high school and university students. By using hand-held devices, students investigate outdoors to determine the source of a toxin spill on their campus. Some ways of investigation are by taking interviews with virtual people, conducting environmental measurement simulations and analyzing the data.

Another application is a mobile city game called "Frequency 1550" [14]. It was developed by the Waag Society and helped students to acquire historical knowledge of medieval Amsterdam. An experimental design used 458 students from 20 classes of 5 different schools and its results showed that students who played the game and were engaged in the project gained more ended regular projects.

\subsection{Determining player's position and navigation}

The main theme on Location Based Games is to determine the player's position as more accurate as you can. There are many approaches, we already mentioned some. GPS, cell tower triangulation, $\mathrm{Wi}-\mathrm{Fi}$, single cell tower and IP are the most used. In some cases, RFID tags may be handy [24].

GPS is the most popular technology for this scope due to its high accuracy. It is consisting by a GPS sensor which is discoverable by the GPS satellites. Because of that it is available everywhere without the need of a tower cell or any other signal. Some problems are inside closed spaces, like buildings etc. Another disadvantage is the high energy consumption although many devices nowadays have enough reserve [37].

A combination of methods is the best and most accurate way of locating the device, eliminating the environment factor [22] [24]. Modern localization techniques, more accurate are being explored to solve more complex problems than locating a player in a game, like navigate autonomous cars [38].

Another basic feature which many, but not all, have is a navigation system mostly provided by a map. The map can be considered as the board, the digital representation of the real world, the representation of the game arena. On a map, more information can be revealed, referenced on a certain position and a physical space. The map can be conceived as a cognitive tool in navigation and gameplay [39].

\subsection{Pattern of Location Based Games}

Every Location-Based game is built on a pattern on how it moves the player around. Search and Find refers to the games that guide the players to specific location, so they can interact through the virtual world with their- real-life surroundings. It is the same pattern for games that gives a multiple choice to the player to go and play. It is the main pattern for data-acquisition Location-Based Games.

Follow the path is another pattern on these games. Like the previous pattern the player must reach a destination, but the attention is given on the path and not on the finish. It may come with penalties for leaving the specified routes etc. The route of the player can also be recorded to draw an object by the lines made by his path. Follow the path is the most used game pattern for treasure hunts.

Chase and catch as we can understand by its name is referred to a pattern in which the player has to chase a moving object or another player. The difference here is that the destination is changing by the time. A mentionable but not much used pattern is the Change of distance in which the player must come close or go far from a location to interact with the game [22].

\subsection{Learning History of Venetian Walls in the digital era}


The Gates of Heraklion consist a remarkable element of the Venetian Walls of the city. The Venetian Walls are a series of fortifications and defensive walls that surround the center of Heraklion. They are one of the best-preserved fortifications of Europe. Their goal was to protect the coastal city from invaders, fact that is proven by the Siege of Candia that lasted for 21 years (1648-1669) and it is the second longest recorded siege in history.

They were first built by the Byzantines although they started being shaped to the way they look nowadays, after the conquest of the city by the Arabs (Saracenes) in 824 . A full reconstruction of the walls took place after the island of Crete fell into Venetian control in 13th century.

Municipality of Heraklion in its application "A Tour of Venetian Candia" for its visitors, the Candia of 1640 is enlivened through a dynamic implementation of a virtual tour, allows the user (inhabitant, visitor, and educational community) to travel digitally through time and space and draw multileveled and diverse information in Greek and English. As the user moves, the application within the old city limits, through specific routes, the Venetian Candia unfolds in front of his/her eyes. An "experiential" in physical space and real-time tour of the historic town center, through new technologies and photorealistic threedimensional representations [40].

Another application is "E-Guide to the Modern City", which is a contemporary electronic city tour guide for smart mobile devices where the user can tour the city sights in an attractive aesthetic environment, with many photographs, text and audio tours depending on the interests and time. For guests who do not have enough time for extensive tours, the "top ten" offers the most important sights of the city, while the "automatic audio guide" gives information about the monuments located in their way [40].

The work presented in this paper defers from the above application as it follows the game based learning approach which improves motivation and enhances engagement of the player. Our LBG offers knowledge through a game by searching places and answering questions. The structure of the game, the subject matter and the questions involve real historical information and in essence, the game becomes a vehicle that transfers information to the player [37].

\section{The Heraklion Fortification Gates LBG}

\subsection{Description of the Game}

The "Heraklion Fortification Gates LBG" is a game that gives players the opportunity to explore Heraklion in a playful way.

At first, the game locates the player's position and then gives him or her instructions on how to get to a specific location. During the search of the location, cards with information about the place the player has to go are displayed on the screen. When the player reaches the required area, she/he should scan with her/his smart device this area for a pattern, in order to have the $3 \mathrm{D}$ augmented reality object appear on her/his screen. When she/he finds it, a question about the place with four possible answers will appear. After answering the question, the player is prompted to take a selfie and moves on to the next place. At the end of game, the player can see the solutions and find out which of them she/he answered correctly and which wrong and all the selfies she/he took in each stop (see Fig. 3 \& Fig. 4).

The "Heraklion fortification gates" is a game for smart devices. The few things that players need are a smart device with a camera (smart phone, tablet) and zest for knowledge. Once the game is downloaded into the device, the user can initiate the learning experience by login into the game. After login, the camera of the device is activated and starts reflecting the real surrounding environment as background on the device's screen.

\subsection{Implementation}

The use of localization technology makes it possible to locate the player's position and display the game elements depending on the location. Our LBG, as all Location Based Games do, builds upon the physical world, and with the addition of a virtual world (AR) it enables the interaction of physical and other related (cultural, historical etc.) data with the player.

For the virtual word in our game we have used Vuforia5 [41] [42] which is an AR Software Development Kit (SDK) for smartphones or other similar mobile device that allows the execution of AR applications into a real-time video obtained from these devices. This software uses the capabilities of the computer vision technology to recognize and make the individual tracking of the objects captured by the video camera in real time.

As basic technology for our game development, we have used the Unity Game Engine [43] which allows the developer to create $2 \mathrm{D}$ or $3 \mathrm{D}$ games. It combines a design platform with $\mathrm{C \#}$ or JavaScript code. The outcome can be exported in different platforms. 


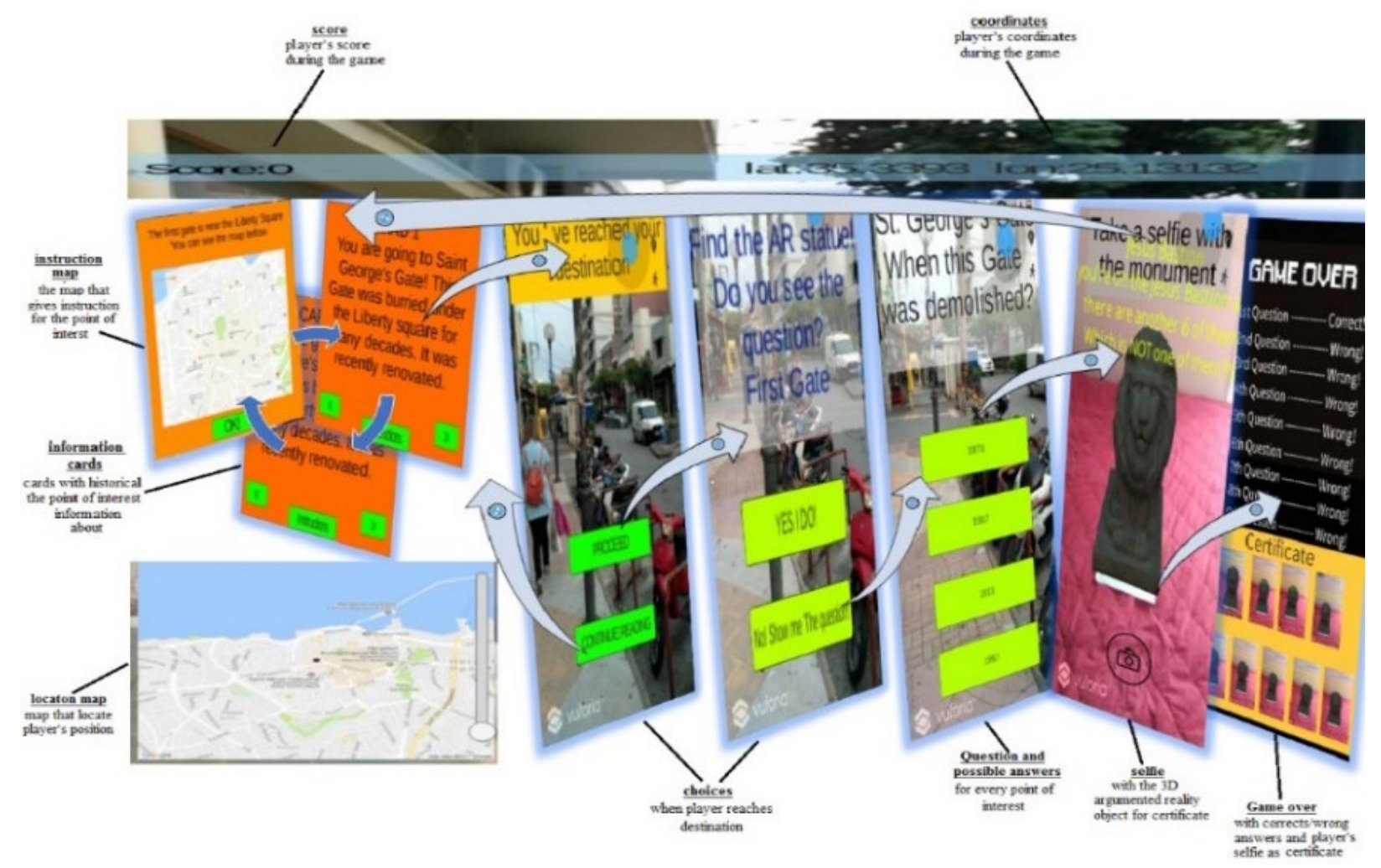

Figure 1. Game Graphical Presentation \& Pattern

Furthermore, we have used innovative pedagogical approaches for the learning aspect of our game. We mixed the art of traditional storytelling and the use of multimedia technology and thus compiled digital storytelling. By digital storytelling students can be engaged in deep, meaningful learning and enhance their motivation. Digital storytelling provides students with opportunities to organize information in a more familiar way and echoes their use of technology outside of the classroom [4].The interaction space of the game is divided into three main areas, which act independently or in combination to each other, depending on the game pattern section and the game storytelling stage. These areas are: (a) the top of the device screen which is a bar with informative data, such as scoring and GPS coordinates (see Figure 1, Figure 2 and Figure 3) with no interaction capabilities, (b) the middle area of the device screen, which presents instructions prompting the player to move to the next point of interest and information about these points, and quiz questions and (c) the lower screen area which shows an open layer map which locates the player's position when acting independently and answers to multiple choice questions when acting in combination with the rest of the game screen.
During the game, the player is notified about the score and coordinates by information which appears on the upper right corner of the screen. As soon as the player is located within the radius of the point of interest, a menu is activated that enables him or her to either proceed to the game flow or continue reading the information cards with the historical data of the point of interest. With the option "PROCEED", the player is encouraged to find the AR element which is a projection of a $3 \mathrm{D}$ augmented reality object (see Figure 2). If the player succeeds on identifying the augmented reality object, a 3D object will be displayed on the screen, and the question will appear in a 3D form. The player then can interact with the 3D AR object by selecting the "YES I DO" option and display possible answers to the quiz question.

In case that the player scans the surrounding place with her/his smart device and cannot locate the 3D augmented reality object, she/he can select the option "NO! Show me the question" and bypass the $3 \mathrm{D}$ and AR options of the game. A question in 2D form will appear and simultaneously one mark will be subtracted from her/his game score as a penalty for not locating the AR object.

The scoring scheme of the game is as follows: +1 if the answer is correct, 0 if it is wrong, -1 if the player does not locate the AR object (see Figure 3). 


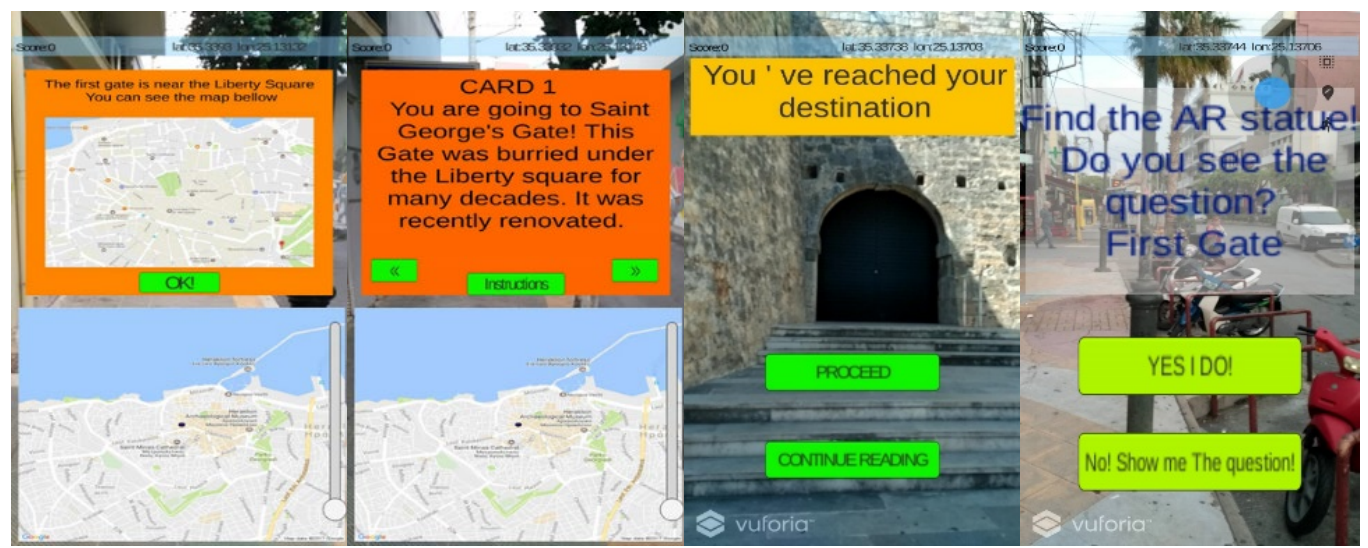

Figure 2. Learning History \& Locating the Point of Interest

In every question the player completes, either in a $2 \mathrm{D}$ or a $3 \mathrm{D}$ question, she/he is asked to take a photograph with the monument and / or the 3D AR object that belong to the point of interest. When the rewarding selfie has been taken the player proceeds to the next point of interest i.e. the next fortification gate of the Heraklion Venetian walls. The map appears again and the steps described above are repeated. By visiting all points of interest, answering all the questions and taking all the rewarding selfies, the game reaches the end. The player is informed with the score, correct and wrong answers and receives the certificate which is a compilation of all taken photographs from each point as reward (see right screen shot of Figure 3).

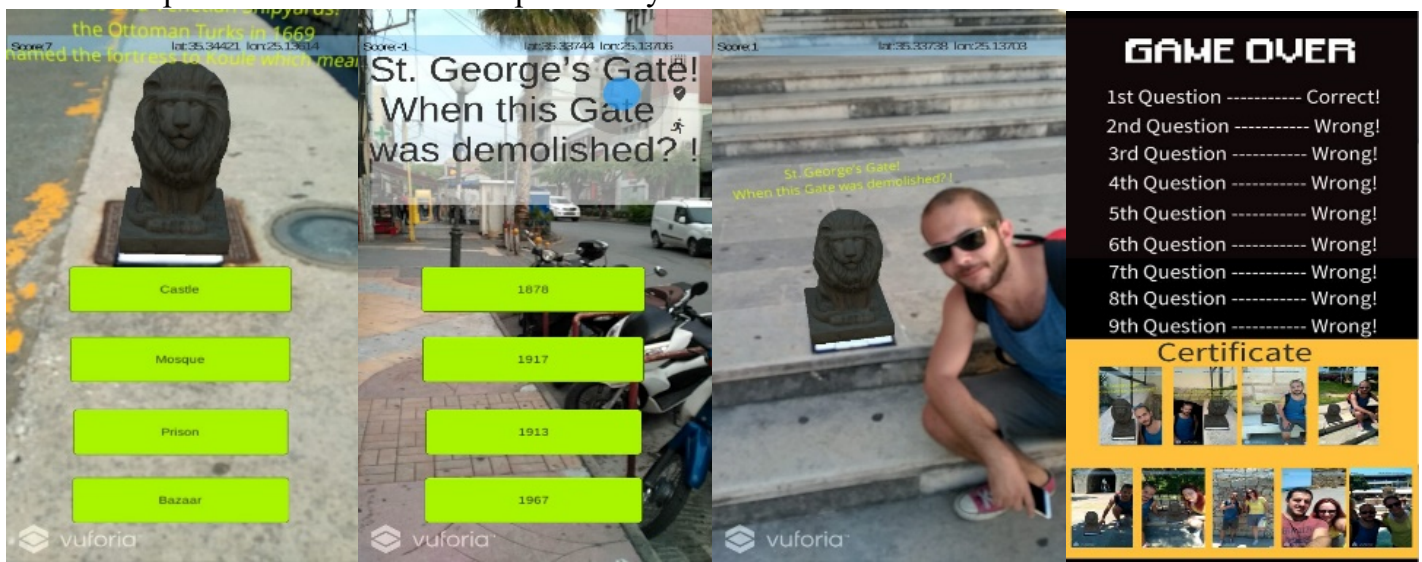

Figure 3. Quiz with or without AR \& Player Rewarding

\subsection{Player's position \& game patterns}

Determining players' position and defining the game patterns are important architectural elements, in order to create engaging games. In our game architecture (see Fig. 3 \& Fig. 4) we thoroughly define those elements and support player positioning and game pattern. In the following paragraphs, we elaborate further these architectural elements.

Determining player position: The main problem on Location Based Games is to determine the player's position as more accurate as you can. There are many approaches for doing so, such as: GPS, cell tower triangulation, Wi-Fi, single cell tower and IP. In more detail, Cell- Id is based on geolocating a smartphone [22]. Using the connected celltower the mobile telephone provider can locate through the id of the tower. IP geolocating is an interesting approach of determining the position of a mobile device. Although the IP is unique for its device, it changes really fast and furthermore, similar IPs may be used in different places. Other methods use Radio-frequency Identification (RFID) tags to identify smart devices with RFID readers installed, or QR-codes etc. A combination of methods is the best and most accurate way of locating the device, eliminating the environment factor. [13]

In our implementation, we use GPS to determine the player's position. GPS is the most popular technology for this scope due to its high accuracy [22]. It consists of a GPS sensor which is discoverable by the GPS satellites. Because of that, it is available everywhere, without the need of a tower cell or any other signals. It is expected to face problems regarding the signal within close spaces, like buildings etc. Another disadvantage is the high energy consumption although many devices nowadays have enough reserve. 
Game Pattern: Every Location-Based game is built on a pattern, so that the player can use it to move around. "Search and Find" pattern refers to the games that have instructions and guide the players to a specific location. Instead of asking the player to move in specific coordinates, this pattern may let the player find a specific object, such as a monument, a school or a store.

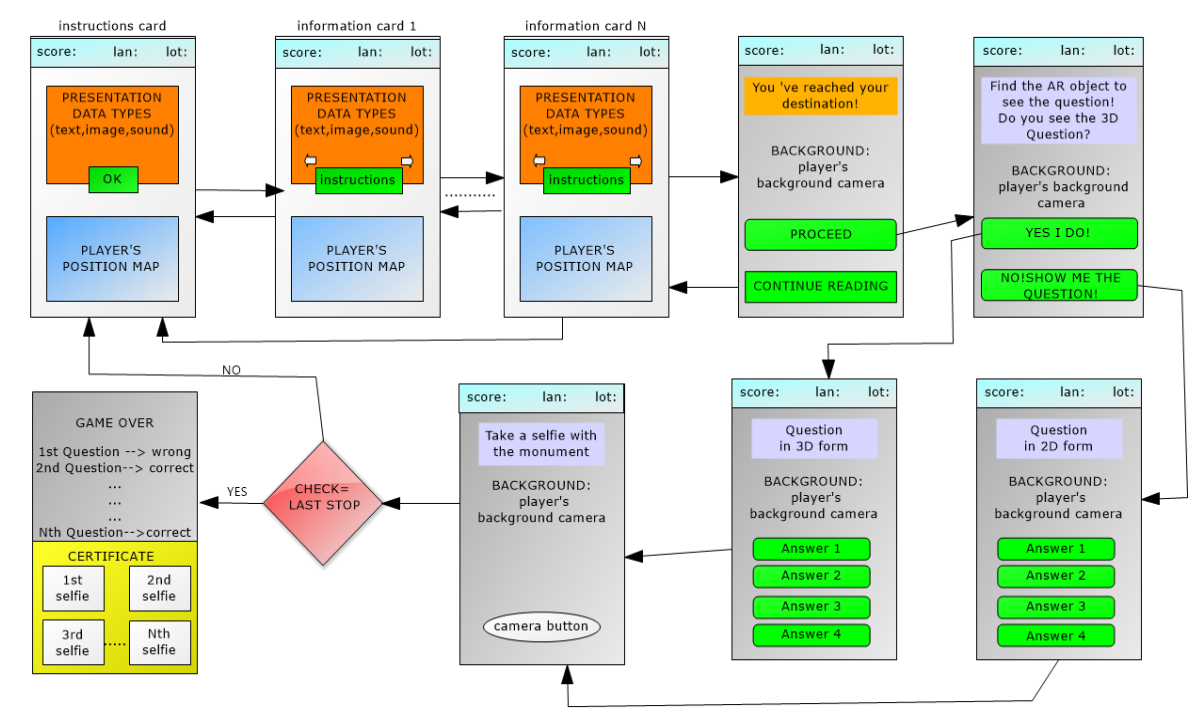

Figure 4. Flow diagram of the game

Our game is using this pattern, as it leads the player through the city of Heraklion, so they can find the spots of interest (gates and bastions) and answer the questions. While moving around, the player is presented with useful information about the destination gate in the form of text, mini videos and photos. Figure 4 presents our game flowchart which is according to the game pattern approach. More specifically, the player is provided with instructions as to how she/he will reach the next point of interest. While moving around toward the next location the game provides educational information about the location in the form of text, mini-videos and sound. The player can navigate between information and instruction as she/he pleases until the next point of interest, as shown in the upper row of the flow diagram of Figure 4. According to our game pattern once the player has reached a point of interest she/he is immediately notified by the game and can decide to look for the AR artifact or not. The decision about the AR artifact affects the interaction elements of the next steps of the game, as presented in rows two and three of Figure 4. Once the player has played the quiz, she/he is permitted to take a selfie with the AR element at the point of interest, as a reward for achieving an intermediate goal. The above flow of events is repeated until the player visits all points of interest and according to our game pattern, she/he will receive a game certificate, which is an assemblage of all points of interest selfies with the AR elements.

\subsection{Use Case Scenario \& Tests}

\section{Scenario}

To present initial test results of our LBG for the Fortification Gates of the Venetian walls of the city of Heraklion and to provide insight into testing outcomes we used a minimalistic scenario according to which the first results were obtained. This scenario is briefly described as a representative use case scenario emphasizing on learning history by playing (Exhibit 1).

Exhibit1: The game scenario takes place at the Fortification Gates of the Venetian walls of the city of Heraklion. The players are called to visit different locations close to the fortification gates. The game constructor can choose a given number of the following 9 game locations to set up the game: St.George's Gate, Vitturi Gate, Jesus Gate, Bethleem Gate, Pantocrator Gate, St.Andrew's Gate, Dermatas Gate, Koules Fortress, Lions' Square. During game play the player is asked to complete various querying type tasks while in location such as answering text based questions or questions based on AR figures. 


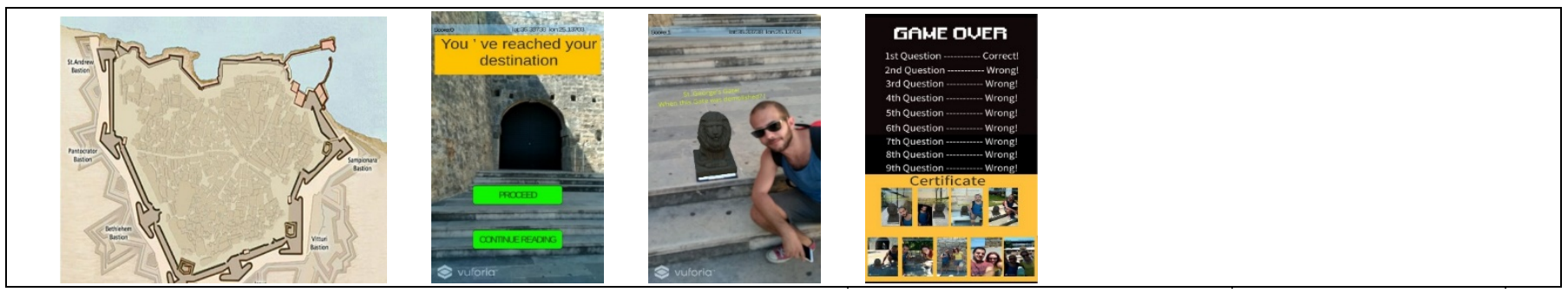

Tests

The tests of our LBG were performed with different Android devices as presented in Table 1. The set of players were 9, male and female, undergraduate and postgraduate students. Open group Discussion prior to game, group interviews after playing and analysis of gameplay from game log.

Table 1. List of mobile devices used for testing

\begin{tabular}{|l|c|}
\hline Device Name & Android Version \\
\hline Huawei P smart & 8.0 .0 \\
\hline Huawei P smart & 8.0 .0 \\
\hline Nexus 5X & 8.1 .0 \\
\hline Samsung Galaxy S9 & 8.0 .0 \\
\hline Samsung Galaxy J6+ & 8.1 .0 \\
\hline Sony Xperia Z5 & 7.0 .0 \\
\hline Samsung Galaxy S8 & 7.1 .0 \\
\hline Honor 9 Lite & 8.1 .0 \\
\hline Xiaomi Mi 5 & 7.1 .1 \\
\hline
\end{tabular}

Table 2. Test runs \& preliminary results

\begin{tabular}{|c|l|}
\hline $\begin{array}{c}\text { Run } \\
\text { No }\end{array}$ & \multicolumn{1}{|c|}{ Test run Description \& Outcomes } \\
\hline $\mathbf{1}$ & $\begin{array}{l}\text { indoor testing } \\
\text { To ensure that the application was running properly, the first test run of the } \\
\text { "Heraklion Fortification Gates LBG" was performed indoors and the position of } \\
\text { the player was determined via a location spoofer application. The GPS location } \\
\text { of the smartphone was given manually while the player remained stable in the } \\
\text { same position. The indoors testing was successful and we proceeded testing } \\
\text { outdoors. } \\
\text { The indoor testing was performed with 2 players (Huawei P smart 8.0.0 and } \\
\text { Xiaomi Mi 57.1.1) } \\
\text { Players finished game (Successful players 100\%, unsuccessful 0\%) } \\
\text { Players' Querying scores (Successful players 100\%, unsuccessful 0\%) }\end{array}$ \\
\hline $\mathbf{2}$ & $\begin{array}{l}\text { outdoor testing, text querying only } \\
\text { For the second test run, the team tested the application outdoors by visiting the 9 } \\
\text { spots determined by the game: St.George's Gate, Vitturi Gate, Jesus Gate, } \\
\text { Bethleem Gate, Pantocrator Gate, St.Andrew's Gate, Dermatas Gate, Koules } \\
\text { Fortress, Lions' Square. } \\
\text { The testing included answering questions given inside the game without the use } \\
\text { of the AR-figure. The outdoor testing was completed successfully and we } \\
\text { proceeded to the next test run outdoors. } \\
\text { Test run 2 (outdoors) was performed with all 9 players } \\
\text { Players finished game (Successful players 100\%, unsuccessful 0\%) } \\
\text { Players' text Querying scores (Successful players 66.66\%, unsuccessful } \\
33.33 \% \text { ) }\end{array}$ \\
\hline $\begin{array}{l}\text { outdoor testing, AR querying only } \\
\text { The third test run, was performed outdoors by visiting the spots mentioned } \\
\text { above. In addition, in this test run, the team used the AR figure option to answer }\end{array}$ \\
\hline
\end{tabular}




\begin{tabular}{|c|c|}
\hline & $\begin{array}{l}\text { the questions. } \\
\text { Test run } 3 \text { (outdoors) was performed with all } 9 \text { players } \\
\text { Players finished game (Successful players } 100 \% \text {, unsuccessful } 0 \% \text { ) } \\
\text { Players' AR Querying scores (Successful players } 44.45 \% \text {, unsuccessful } 55.55 \% \text { ) }\end{array}$ \\
\hline \multirow{5}{*}{4} & outdoor testing, text \& AR querying \\
\hline & $\begin{array}{l}\text { The final test run, was performed in a real life scenario where the choice of } \\
\text { using and not using the AR figure was random. The team used both options and } \\
\text { completed the game successfully. }\end{array}$ \\
\hline & Test run 4 was performed with all 9 players \\
\hline & Players finished game (Successful players $100 \%$, unsuccessful $0 \%$ ) \\
\hline & $\begin{array}{l}\text { Players' text Querying scores (Successful players } 77.78 \% \text {, unsuccessful } \\
22.22 \% \text { ) } \\
\text { Players' AR Querying scores (Successful players } 55.55 \% \text {, unsuccessful } 44.45 \% \text { ) }\end{array}$ \\
\hline
\end{tabular}

\section{Conclusion}

Location Based Games in education could be the way for producing learning outcomes by increasing the motivation and interest of students about subjects that demand sightseeing. Current handheld devices (smartphones, tablets, etc.) with embedded geolocation technologies and video cameras are ideal medium for such games. Usually, LBG require from the player to move around in order to complete a task and proceed through a storyline. School outdoor activities would be more fun and more pedagogic with the use of LBG adapted in a learning context.

In this paper, we've introduced "The Heraklion Fortification Gates", a LBG that offers to students the opportunity to learn about the history of the Venetians gates of the city of Heraklion. When the student reaches the place of interest she/he gets information about the gate and has to answer to related questions. The game arena is the physical space of the city, while the visual display environment consists of both physical and virtual worlds. Furthermore augmented reality is used in the form of 3D objects. The structure, the thematic area and the questioning mechanisms of our game involve actual historical information which result to added educational value. In that respect our game follows the 'game based learning' and the 'learn by playing' philosophy and becomes a vehicle to knowledge. Preliminary test results showed: (a) a positive attitude towards the game, especially in conjunction with the history learning process, (b) that LBGs could be used as a teaching method and (c) not necessarily useful for all students especially the text and AR querying techniques.

The new version of the game would have a background scenario for leading the player from place to place. Also a story, perhaps a crime-solving story, that lead the game-flow could make the LBG more ludic and increase further the interest of the players.

\section{References}

[1] L. S. Vygotsky, "Play and its role in the mental development of the child.," in Soviet psychology $5.3: 6-18 ., 1967$.

[2] M. Prensky, "J COMPUTER GAMES AND LEARN| NG: D 1 G ITAL GAME-BASED LEARN 1 NG," 2007.

[3] A. Marczewski, "Gamasutra-The Art \& Bussiness of Making Games," 2013.

[4] D. Flatla, C. Gutwin, L. Nacke, S. Bateman and R. Mandryk, Calibration Games: Making Calibration Tasks Enjoyable by Adding Motivating Game Elements, 2011.

[5] F. De Grove, J. Bourgonjon and J. Van Looy, "Digital games in the classroom? A contextual approach to teachers' adoptionintention of digital games in formal education," ELSEVIER, 20 June 2012.

[6] M. Weiser, "The Computer for the 21st Century.," Scientific American, September 1991.

[7] P. Milgram and F. Kishino, "Taxonomy of Mixed Reality Visual Displays.," IEICE TRANSACTIONS on Information and Systems, pp. 1321-1329, 25121994.

[8] Y. Nikoloudakis, S. Panagiotakis, E. Markakis, C. Mavromoustakis and E. Pallis, "Towards a FOG-enabled navigation system with advanced cross-layer management features and IoT equipment.," in Cloud and Fog Computing in 5G Mobile Networks: Emerging Advances and Applications 70 (2017): 171., 2017.

[9] Lee Y. H., Kim R. H., "Estimation of the Smartphone User' Satisfaction and Customer Intention on the Social Networking Service," in International Conference on Applied Human Factors and Ergonomics, 2018.

[10] George H. Forman, John Zahorjan,, "The Challenges of Mobile Computing," Computer, pp. 38-47, 1994.

[11] Mike Sharples, Josie Taylor, Giasemi Vavoula, "A Theory of Learning for the Mobile Age," The Sage Handbook of Elearning Research, pp. 221-247, 2006.

[12] E. FitzGerald, R. Ferguson, A. Adams and M. Gaved, "Augmented reality and Mobile Learning: The State of the Art.," International Journal of Mobile and Blended Learning, pp. 43-58, 2013.

[13] Linwan $\mathrm{Wu}$, Matthew A. Stilwell, "Exploring the marketing potential," Journal of Research in Interactive Marketing, 2017.

[14] Huizenga J., Admiraal W., Akkerman S., \& Dam G., "Mobile game-based learning in secondary education: engagement, motivation and learning in a mobile city game.," Journal of Computer Assisted Learning, pp. 332-344, 2009.

[15] Jo Dugstad Wake, Frode Guribye, Barbara Wasson, "Learning through collaborative design," International Journal of Computer-Supported Collaborative Learning, pp. $1-21,2018$ 
[16] J. J. Lee and J. Hammer, Gamification in Education: What, How, Why Bother?, 2011.

[17] N. Vidakis, E. Christinaki, I. Serafimidis and G. Triantafyllidis, "Combining Ludology and Narratology in an Open Authorable Framework for Educational Games for Children: the Scenario of Teaching Preschoolers with Autism Diagnosis," in UAHCI 2014, Held as Part of HCI International 2014, Heraklion, Crete, Greece, 2014.

[18] N. Smeda, E. Dakich and N. Shanrda, "The Effectiveness of Digital StoryTelling in the Classrooms: A Comprehensive Study.," Smart Learning Environments, 3 December 2014.

[19] C. Shelby-Caffey, E. Úbéda and B. Jenkins, "Digital Storytelling Revisited. An Educator's Use of an Innovative Literacy Practice (2014)," The Reading Teacher, 10 Juny 2014.

[20] N. Vidakis, E. Syntychakis, K. Kalafatis, E. Christinaki and G. Triantafyllidis, "Ludic Educational Game Creation Tool: teaching schoolers road safety," in UAHCI 2015, Held as Part of HCI International 2015, Los Angeles, CA, USA, 2015.

[21] G. R. Duncan, "Gamers turn cities into a battleground," New Scientists, 12 June 2005.

[22] L. Lehmann, Location-based Mobile Games.

[23] C. Sintoris, N. Yiannoutsou, S. Demetriou and N. Avouris, "Discovering the Invisible City: Location-Based Games for Learning in Smart cities.," Interaction Design and Architecture(s) Journal, pp. 47-64., 2013.

[24] Rashid, O., Mullins, I., Coulton, P., \& Edwards, R., "Extending cyberspace: location based games using cellular phones," Computers in Entertainment (CIE), 2006.

[25] Schlieder, C., Kiefer, P., \& Matyas, S, "Geogames: Designing location-based games from classic board games.," IEEE Intelligent Systems, pp. 40-46, 2006.

[26] O. Ahlqvist, "Location-Based Games," International Encyclopedia of Geography: People, the Earth, Environment and Technology: People, the Earth, Environment and Technology, pp. 1-4, 2016.

[27] M. Wijers, V. Jonker and P. Drijvers, "MobileMath: Exploring Mathematics Outside the Classroom," Mathematics Education, pp. 789-799, 2010.

[28] P. Daponte, L. De Vito, F. Picariello and M. Ricci, "State of the Art and Future Developments of the Augmented Reality for Measurement Applications," ScienceDirect, p. 53-70, November 2014

[29] J. Bacca, S. Baldiris, R. Fabregat, S. Graf and Kinshuk, "Augmented Reality Treands in Education: A Systematic Review of Research and Applications.," Educational Technology \& Society,17, pp. 133-149, (2014).

[30] P. Milgram, H. Takemura, A. Utsumi and F. Kishino, "Augmented reality: a class of displays on the realityvirtuality continuum.," Teleman. Telepres. Technol., p. 282292, 21121995

[31] S. Björk, J. Falk, R. Hansson and P. Ljungstrand, Pirates! Using the Physical World as a Game Board, (2001).

[32] S. Benford, R. Anastasi, M. Flintham and A. Drozd, "Coping with uncertainty in a location-based game.," IEEE Pervasive Computing, pp. 34-41, July (2003).

[33] E. Brown, D. Börner, M. Sharples, C. Glahn and T. De Jong, Location-based and contextual mobile learning. A STELLAR Small-Scale Study., (2010).

[34] R. Mayer, "Cognitive Theory and the Design of Multimedia Instruction: An Example of the Two-Way Street Between Cognition and Instruction.," New Directions for Teaching and Learning, March 2002.

[35] J. Joo-Nagata, F. Abad, J. Giner and F. Garcia-Peñalvo, ": Augmented Reality and Pedestrian Navigation through its
Implementation in M-learning and E-learning: Evaluation of an Educational Program in Chile.," Computers \& Education, pp. 1-17, 2017.

[36] MIT, "MIT Handheld Augmented Reality Simulations," 2003. [Online]. Available: MIT Handheld Augmented Reality Simulations. [Accessed June 2017].

[37] Djuknic, G. M., \& Richton, R. E., "Geolocation and assisted GPS," Computer, pp. 123-125, 2001.

[38] Kuutti, S., Fallah, S., Katsaros, K., Dianati, M., Mccullough, F., \& Mouzakitis, A., "A Survey of the State-of-the-Art Localization Techniques and Their Potentials for Autonomous Vehicle Applications.," IEEE Internet of Things Journal, pp. 829-846, 2018.

[39] Lammes, S., \& Wilmott, C., "Mapping the City, Playing the City: Location-based Apps as Navigational Interfaces.," Convergence, 2016.

[40] M. o. Heraklion, "Municipalty of Heraklion: Mobile Applications. (2015)," [Online]. Available: https://www.heraklion.gr/ourplace/her-mobileapps/heraklion-mobile-apps.html. [Accessed 26 2017].

[41] "Vuforia Developer Portal," PTC Inc., 2011. [Online]. Available: https://developer.vuforia.com/. [Accessed 2 May 217].

[42] A. Ibanez and J. Figueras, Vuforia v1.5 SDK: Analysis and Evaluation of Capabilities., (2013).

[43] "UNITY," UNITY, [Online]. Available: https://unity3d.com/. [Accessed 10 April 2017]. 